substantially reduced if the demand became large enough. As the auxiliary apparatus required is not excessive, and can be assembled from standard components, the system is quite practicable for domestic use.

\section{New Electric Lamps}

Is a paper read to the Royal Society of Arts on March 7, Mr. J. W. Ryde of the G.E.C. Research Laboratories, Wembley, gave a full account of the working of the new electric discharge lamps. The sodium discharge lamp is practically monochromatic and of a brilliant yellow colour. Hence coloured objects illuminated by it all appear to be various shades of brown. Its efficiency, about 40 lumens per watt, although three times that of the ordinary filament lamp, is yet only about a tenth of the maximum possible yellow light that could be obtained for the same power. It is well known that the efficiencies of all kinds of electric lamp vary with their life. The problem of candle power maintenance is one that constantly engages the attention of every lamp manufacturer. In spite of years of research, the light output of incandescent filament lamps still drops by a certain amount after several hundred hours burning. The candle power maintenance for the new lamps has now been raised to a reasonable figure, but it is recognised that considerable improvements are possible. It is rapidly approaching that of the filament lamp. At present there is no sign that the eminently simple and highly developed filament lamp will shortly be replaced by discharge lamps for purposes of indoor illumination; but it must be admitted that discharge lamps will play an ever increasing part in the future of electric lighting. Already there are 65 street lighting installations for which these lamps have been adopted. Street lighting is the one use of artificial lighting for which we have never produced enough light. The use of the new lamps is an excellent opportunity of improving the lighting of our streets at little, if any, increase in the cost.

\section{Importance of Deep Borehole Surveying}

DESIGNERS of apparatus for surveying deep boreholes have in the past consistently underestimated difficult engineering problems necessarily attendant on such surveys. On April 10, W. E. Bruges read a paper before the Institution of Petroleum Technologists in which he made some pertinent remarks on the usefulness of well surveys as an adjunct to drilling logs and geological data. Geologists can utilise the results of accurate surveys for correcting underground contours, choosing such surface locations as will ensure economic spacing of wells in the oilsand below and making deductions as regards the formation as a whole from direction, deviation and irregularities of the hole as portrayed by the survey. Administration is facilitated by a knowledge of exact spacing of wells in an oilsand. Decisions regarding drilling activities can be taken with confidence, and the risk of overcrowding, hence decreasing production, is minimised. Recent experiments in Burma have shown that of available apparatus for this work, that designed and manufactured by Martienssen is the most satisfactory. The instrument is fitted with a gyroscope for obtaining direction and two pendulums for inclination, results being recorded photographically. It has the advantage that the gyroscope is unaffected by magnetic influences, while the pendulum method of obtaining inclinations allows a number of readings to be taken at one run. Photographic recording of results means that the instruments below ground can be light, obviating necessity of following. up gear ; moreover, their relative places in the well can be photographed without disturbing position or setting.

\section{Automobiles Run by Charcoal Fuel}

IN Italy, automobiles have recently been operated on a gas fuel made in transit from charcoal and steam. It is recalled in a recent paragraph issued by Science Service, of Washington, D.C., that similar experiments were made in France and other European countries several years ago. The principle involved is the same as that used in the manufacture of some kinds of gas employed in operating stationary internal combustion engines. A carbon-containing material, usually coal, is heated, and then water in the form of steam is passed over it. Carbon monoxide and hydrogen are formed in this process and both these gases burn with high heat output. Mixtures of this sort are known as 'water' gas or 'producer' gas. This gas can be used as fuel in internal combustion engines. The drawback to using these gas engines in motor vehicles is the difficulty of carrying the fuel supply. In permanent locations they can be used very effectively for power generation. To a limited extent, vehicles that run on wood or charcoal and manufacture their own gaseous fuel as they go along are used commercially in France. Science Service points out that this type of self-propelled vehicle may become important in countries like France and Italy which have no petroleum supplies within their borders. In the United States, on the other hand, owing to the cheapness and availability of petroleum, there would be no need for this kind of vehicle. In those countries where imported oil supplies are likely to be interrupted in war time, automobiles using charcoal fuel would have advantages.

\section{Science and Industry in the U.S.S.R.}

IN a recent publication entitled "Organisation et Principes de L'Enseignement en U.R.S.S." (Paris : Hermann et Cie, 6 Rue de la Sorbonne) Prof. Jean Trillat gives an interesting description of the relations between science and industry in Soviet Russia. One of the most important transformations brought about by the Russian revolution has been the establish. ment of compulsory education, and this in turn has led to a considerable development of scientific studies. Prof. Trillat points out that in order to understand correctly the nature of educational and scientific progress in Russia, it is essential to remember that there such developments have been 
based on a materialistic philosophy. The religious mysticism of pre-War Russia has now been replaced by the mysticism of the machine. The conception of science in Soviet Russia is that of an auxiliary to socialism. Education figures as a definite part of the Five Years Plan, and the Educational Plan comprises a general scheme of public education, the preparation of technicians and scientific workers from among the working classes, together with a general scheme of scientific research and the establishment of numerous scientific institutes. The author describes a number of these institutes which he visited, including the physico-technical "Kombinat" at Leningrad with its subsidiary institutes of physical chemistry and electro-physics. In addition, it has an experimental workshop of a unique character which manufactures scientific instruments for the "Kombinat" and other institutes. Employing about 300 workers, it is a half-industrial and halfscientific organisation. Soviet industry has thus behind it very extensive means for scientific research, and the various problems, classified according to interest or urgency, are investigated by the specialised chemical, physical or electrical institutes.

\section{Chemical Researches in Czechoslovakia}

Ever since the middle of last century, much chemical research work has been carried out at Prague. Some of the investigations, notably Prof. B. Brauner's work on atomic weights and on the rare earth elements, attracted wide attention, but much valuable, if less spectacular, work was overlooked. Few Czech men of science published in English journals; the majority of their researches appeared in the little-read Czech publications. To direct more attention to their achievements, Czechoslovak chemists founded in 1928 under the joint editorship of Profs. Votoček and Heyrovský the Collection of Czechoslovak Chemical Communications, in which the contributions were written in French or English. Among the more interesting contributions that have appeared recently in this journal mention may be made of the diseovery by Prof. Křepelka and Dr. Novotný that mercurous halides show marked triboluminescence, the actual intensity depending on the conditions of preparation. Prof. Simek has also made some observations on the curious electrical behaviour of fused tellurium dioxide. In organic chemistry, Drs. Landa and Machaček have described a new solid hydrocarbon, $\mathrm{C}_{10} \mathrm{H}_{16}$, to which they assign the name adamantane. A series of researches by Prof. Votoček and his collaborators has cleared up a number of points in connexion with the lesserknown sugars such as rhamnose, rhodeose and fucose. Prof. Heyrovský has also published a series of papers (referred to in NatuRE of March 10, p. 385) dealing with his polarographic studies with the dropping mercury cathode.

\section{The Indian Chemical Society (1924-1932)}

Prof. B. K. Singh's presidential address to the Indian Chemical Society (Journal of the Indian Chemical Society, vol. 10, No. 1, p. 1, 1933) deals with
"Optics in the Service of Chemistry", and includes a review of recent work on optical rotatory power and rotatory dispersion, to which he has himself con. tributed. He also records in a tabular form the growth of the Indian Chemical Society, during the nine years of its existence. During the first five years the growth was rapid, but the Society has held its own during the more difficult years from 1929 until 1932. It now includes 360 fellows and 100 subscribers, and is publishing approximately 100 papers in each year, of which 750 pages are printed free of cost by the University of Calcutta. Under these favourable conditions an income of about $10,000 \mathrm{Rs}$. has usually provided a credit balance, and a reserve fund of $21,000 \mathrm{Rs}$. has been built up, in addition to a donation of $10,000 \mathrm{Rs}$. from Sir P. C. Rây which is earmarked for the provision of a headquarters for the Society.

\section{Schlieren, Striæ or Streaks?}

IN the January issue of the Journal of Scientific Instruments, Mr. T. Smith, of the National Physical Laboratory, raises the question whether it is fair to Foucault to continue to describe the method he introduced for observing small optical differences of path by the name "schlieren" used for the method by Töpler in his paper of 1866 on the motion of singing flames. Messrs. Taylor and Waldram, who had used the term 'schlieren' in their paper in the December issue of the Journal, point out that Töpler in giving the method that name made no claim to its invention but only to an extension of the use of it to general scientific investigations. Would striæ or streaks be adequate equivalents of, and suitable alternatives for, schlieren?

\section{Uniformity in Bibliographical Particulars}

REFERRING to recent correspondence on this subject (Nature, 133, 380, March $10 ; 495$, March 31, 1934), Mr. A. Windelbandt, bibliographer in the library of the Institute of Plant Industry, Leningrad, writes pointing out the practical value of accurately given bibliographical citations in articles and books. Mr. Windelbandt states that footnotes and other references are often given in such a way as to make it impossible to recognise the publication. While the name of the author is quoted, the title of the article is often omitted and sometimes it is difficult to identify the journal owing to the manner in which the name is abbreviated. The absence of the year and volume in the case of articles, and the place of publication and name of publisher in the case of books, also renders it difficult for the reader to find the publication. Lack of pagination, too, may lead to a lengthy search, if a volume has no special index.

\section{Institute of Physics}

The annual general meeting of the Institute of Physics was held at the Royal Institution on May 15. After election of the officers and completion of the panel of the Board, it was announced that the following would take office on October 1 next: President, Sir Henry Lyons; Vice-President, Prof. W. L. Bragg ; Honorary Treasurer, Major C. E. S. 